\section{Effect of royal jelly on experi- mental colitis induced by acetic acid and alteration of mast cell distribution in the colon of rats}

\author{
T. Karaca, ${ }^{1}$ F. Bayiroglu, ${ }^{2}$ M. Yoruk, ${ }^{1}$ \\ M.S. Kaya, ${ }^{2}$ S. Uslu, ${ }^{1}$ B. Comba, ${ }^{2}$ L. Mis ${ }^{2}$
}

'Department of Histology and Embryology, Faculty of Veterinary Medicine, University of Yuzuncu Yil, Van, Turkey

2Department of Physiology, Faculty of Veterinary Medicine, University of Yuzuncu Yil, Van, Turkey

\section{Abstract}

This study investigated the effects of royal jelly (RJ) on acetic acid-induced colitis in rats. Twenty adult female Wistar albino rats were divided into four treatment groups of 5 animals each, including a control group (Group I); Group II was treated orally with RJ (150 mg $\mathrm{kg}^{-1}$ body weight); Group III had acetic acidinduced colitis; and Group IV had acetic acidinduced colitis treated orally with RJ (150 mg $\mathrm{kg}^{-1}$ body weight) for 4 weeks. Colitis was induced by intracolonic instillation of $4 \%$ acetic acid; the control group received physiological saline $\left(10 \mathrm{~mL} \mathrm{~kg}^{-1}\right)$. Colon samples were obtained under deep anaesthesia from animals in all groups. Tissues were fixed in $10 \%$ formalin neutral buffer solution for $24 \mathrm{~h}$ and embedded in paraffin. Six-micrometre-thick sections were stained with Mallory's triple stain and toluidine blue in $1 \%$ aqueous solution at $\mathrm{pH} 1.0$ for 5 min (for Mast Cells). RJ was shown to protect the colonic mucosa against the injurious effect of acetic acid. Colitis (colonic damage) was confirmed histomorphometrically as significant increases in the number of mast cells (MC) and colonic erosions in rats with acetic acid-induced colitis. The RJ treatment significantly decreased the number of $\mathrm{MC}$ and reduced the area of colonic erosion in the colon of RJ-treated rats compared with rats with untreated colitis. The results suggest that oral treatment with $\mathrm{RJ}$ could be used to treat colitis.

\section{Introduction}

The constant exposure of the intestinal epithelium to diverse types of nutrients and microorganisms present in the natural flora leads to permanent stress for enterocytes. Mucosal surfaces of the intestinal tract represent one of the main routes for microbial pathogens to enter a host and are important sites of microbially induced diseases. ${ }^{1}$

Natural compounds, such as components of green tea and RJ, can play a significant role against inflammation, cancer, ${ }^{2}$ cell proliferation $^{3}$ and liver damage. ${ }^{4} \mathrm{RJ}$ is a traditional product commonly used to supplement the medical treatment of various diseases. It is secreted from the hypopharyngeal and mandibular glands of young worker bees, to feed young larvae and the adult queen bee. ${ }^{4} \mathrm{RJ}$ contains many important compounds with biological activity, such as free amino acids, proteins, sugars, fatty acids, minerals (e.g. iron and calcium) and vitamins (mainly thiamine, niacin, riboflavin). ${ }^{5,6}$ Several reports in the literature demonstrate the immunomodulatory properties of RJ.-9

The ability of MCs to release proinflammatory and immunoregulatory mediators has led to speculation that they are involved in gastrointestinal pathologies, such as intestinal allergy, coeliac disease and inflammatory bowel disease (IBD). In patients with IBD, the numbers of intestinal MC are increased. They have been shown to account for 60 and $30 \%$ of all mucosal cells immunoreactive for tumour necrosis factor (TNF)- $\alpha$ and interleukin (IL)5 , respectively. ${ }^{10-13}$ In previous studies, many authors identified changes in MCs in inflammatory bowel diseases, including ulcerative colitis. ${ }^{14,15}$ In addition, in vitro studies with MCs isolated from intestinal tissue demonstrated increased release of histamine and eicosanoids in MCs derived from patients with IBD compared with control patients. ${ }^{16}$ Such data support the hypothesis that MCs are primed or preactivated by the local inflammatory tissue environment. ${ }^{17}$

Intracolonic application of acetic acid has long been used as an artificial method to induce colitis in experimental animals. ${ }^{18,19}$ Although it is known that the MC population in the intestine may be involved in pathological changes in the colon, very few data are available on changes in the number and distribution of MCs in colon of subjects with colitis. These parameters were therefore investigated in this study, which also examined, for the first time, the effect of RJ on numerical distribution of MCs and on the ability of rat colonic mucosa tissue to generate after acetic acidinduced colitis. The aim of the present study was to evaluate the protective and antioxidative effect of RJ in acetic acid-induced colonic damage by determining changes in tissue histology and number of MCs.
Correspondence: Dr. Turan Karaca, University of Yuzuncu Yil, Faculty of Veterinary Medicine, Department of Histology and Embryology, 65080 Van, Turkey.

Tel. +90.432.2251024 - Fax: +90.432.2251127.

E-mail: turankaraca@yyu.edu.tr or

turankaraca74@hotmail.com

Key words: Royal jelly, colitis, mast cell, rat.

Received for publication: 24 May 2010. Accepted for publication: 15 June 2010.

This work is licensed under a Creative Commons Attribution 3.0 License (by-nc 3.0).

(C) Copyright T. Karaca et al., 2010

Licensee PAGEPress, Italy

European Journal of Histochemistry 2010; 54:e35 doi:10.4081/ejh.2010.e35

\section{Materials and Methods}

\section{Animals}

Twenty adult female Wistar albino rats $(n=5 \times 4)$ weighing about $300 \mathrm{~g}$ were obtained from the Laboratory of Animal Science, Medical School, Firat University, Elazıg, Turkey. The animals were given standard rat pellets (Van Feed Factory, Van, Turkey) and tap water ad libitum and were housed in individual cages $\left(360 \times 200 \times 190 \mathrm{~mm}^{3}\right)$, each containing 2 or 3 animals, from 7 days before the start of the experiment.

The rats were divided into four equal groups [Group I - control group, Group II - royal jellytreated (RJ), Group III - acetic acid-treated (Colitis) and Group IV - acetic acid-treated (Colitis) + royal jelly (CRJ)]. Group I received normal food and water during the experiment. Group II received normal food and royal jelly (150 $\mathrm{mg} / \mathrm{kg}^{-1}$ ) suspended in water. Group III received normal food and a dose of acetic acid dissolved in $0.9 \% \mathrm{NaCl}$ delivered via the anus to the colon. Group IV received normal food along with $150 \mathrm{mg} / \mathrm{kg}^{-1}$ royal jelly and a per anus dose of acetic acid dissolved in $0.9 \% \mathrm{NaCl}$.

The RJ used was purchased from a local natural food store, Istanbul, Turkey. All animals were housed in stainless steel cages under standard laboratory conditions (light period $07.00 \mathrm{~h}$ to $20.00 \mathrm{~h}, 21 \pm 2^{\circ} \mathrm{C}$, relative humidity $55 \%$ ), and received humane care according to the criteria outlined in the Guide for the Care and Use of Laboratory Animals prepared by the National Academy of Sciences and published by the National Institute of Health.

\section{Amino acid content of royal jelly}

The amino acid content of the RJ used is given in Table 1 . The main amino acids pres- 
Table 1. Free amino acid content of the RJ used in the experiment $(\mathrm{mg} / 100 \mathrm{~g}){ }^{4}$

\begin{tabular}{lc} 
Aspartic acid & 17.33 \\
Serine & 1.39 \\
\hline Glycine & 1.66 \\
Lysine & 62.43 \\
\hline Cysteine & 1.29 \\
Glutamic acid & 2.99 \\
\hline Threonine & 1.15 \\
Alanine & 1.14 \\
\hline Proline & 58.76 \\
Valine & 3.29 \\
\hline
\end{tabular}

Methionine

Tyrosine $\quad 1.29$

Tryptophan

Histidine

Arginine

Cystine 21.76

Phenylalanine $\quad 1.49$

Hydroxyproline $\quad 1.61$

Leucine-isoleucine

1.51

Glutamine

1.46

ent were lysine (62.4 $\left.\mathrm{mg} 100 \mathrm{~g}^{-1}\right)$ and proline

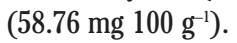

\section{Induction of experimental colitis}

All experimental animals were fasted for 24 $h$ before induction of colitis. Each rat was lightly anesthetised with ether, and a polyethylene cannula was inserted into the lumen of the colon via the anus. The tip of the cannula was positioned at $8 \mathrm{~cm}$ proximal to the anus. Either $1 \mathrm{~mL}$ of acetic acid ( $4 \% \mathrm{vol} / \mathrm{vol}$ in $0.9 \%$ $\mathrm{NaCl}$ ) or saline as the inert control was slowly infused into the distal colon. After 30 seconds exposure, $1 \mathrm{~mL}$ of saline $(0.9 \%)$ was instilled in order to withdraw the previous solution from the colon. ${ }^{18}$

\section{Histological analysis}

One month after experiment beginning, rats were sacrificed under ether anaesthesia and the colon of each animal was excised and gently rinsed under tap water. The colon was then stretched on a piece of cork with mucosal surface upwards in the standard position for macroscopic examination and the severity of colitis was scored with the help of a magnifying glass. Finally, the colon was dissected and fixed in $10 \%$ formalin neutral buffer solution at room temperature for $24 \mathrm{~h}$ and cross-sections were processed routinely for light microscopy. Sections of $6 \mu \mathrm{m}$ were stained with Mallory's triple stain and examined under a light microscope.

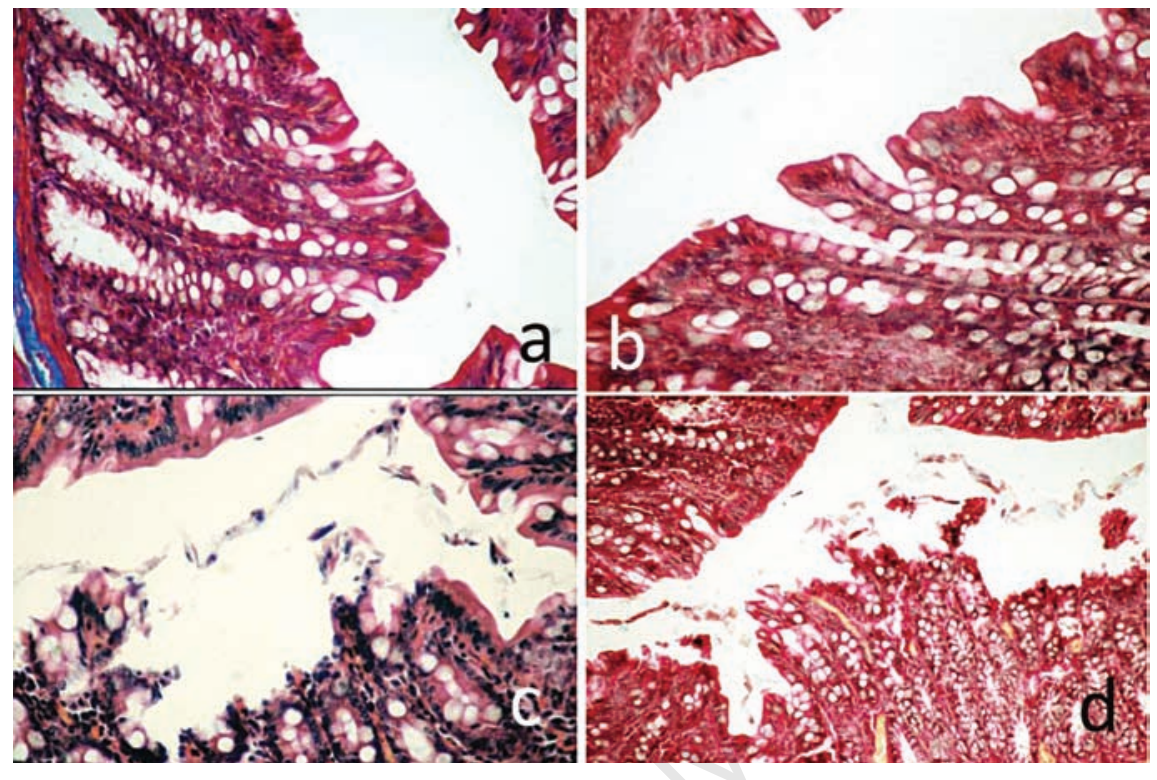

Figure 1. Histological analysis of the colon section. (A) Control group; (B) Royal Jelly group, the section shows normal mucosal glands with intact epithelial surfaces. (C) Colitis group, the section shows a severe damage to the colon mucosa, with including massive destruction of the epithelial layer. (D) Colitis + Royal Jelly group, the section shows a superficial ulceration. Magnification $A, B, C=180 X$ and $D=100 X$. H\&E.

\section{Mast cell analysis}

Colon tissues fixed in $10 \%$ formalin neutral buffer solution for $24 \mathrm{~h}$ were embedded in paraffin. Sections of $6 \mu \mathrm{m}$ thickness were cut and stained with $0.5 \%$ toluidine blue (Gurr, England) in $0.5 \mathrm{~N}$ hydrochloric acid at $\mathrm{pH} 0.5$ for 30 min. ${ }^{20}$ Tissue sections were examined under light microscopy (x400) and the number of MCs per square millimeter were counted in random high-power fields using a Nikon Optiphot 2 (Japan) light microscope incorporating a square graticule in the eyepiece (eyepiece $x 10$, objective $x 40$, a total side length of $0.225 \mathrm{~mm}$ ). Intact and partially degranulated MCs were counted in 100 high-power fields in colon preparations of each group. The MC density at each site was calculated and recorded as MC numbers $\mathrm{mm}^{-2}$.

\section{Statistical analyses}

The results are expressed as mean \pm standard deviation. The Bartlett test was used in order to determine the heterogeneity of the data. The Bonferroni multiple comparison procedure was then utilised for identifying differences among means. Differences were considered significant at $\mathrm{P}<0.05$.

\section{Results}

Light microscopy examination of the colon mucosa of control rats (Group I) and RJ rats
(Group II) stained with Mallory's triple stain showed normal mucosal (crypts) glands with intact epithelial surfaces (Figure 1A, B). The surface epithelium and the crypt architecture were normal, comprising columnar epithelial and goblet cells. The rats with acetic acidinduced colitis (Group III) exhibited severe damage to the colon mucosa, with pathological changes including massive destruction of the epithelial layer and cellular debris, haemorrhagic colitis in the colon mucosa and gross lesions in the colon. The main histological finding was the presence of necrosis associated with haemorrhage. Histology revealed coagulative necrosis of the surface epithelium and some crypts with focal ulceration. Microscopic examination of the colon mucosa showed lesions that varied in extent and depth (Figure $1 \mathrm{C}$ ).

Oral treatment with $150 \mathrm{~mL} \mathrm{~kg}^{-1} \mathrm{RJ}$ gave a protective effect against acetic acid-induced colitis in Group IV rats. The colon mucosa of these rats showed superficial ulceration and slight focal congestion and the crypts appeared normal. Mild cellular infiltration was apparent in the lamina propria and submucosa (Figure $1 \mathrm{D})$, while the protective effect was mild with $150 \mathrm{mg} \mathrm{kg}^{-1}$ dose of RJ.

The numbers of MCs in the colon increased after acetic acid administration, but the number of colonic MCs in the colitis + RJ group (Group IV) was significantly lower than that in the colitis group. The histological appearance and distributions of numbers of MCs is summarized in Figures 2 and 3. 


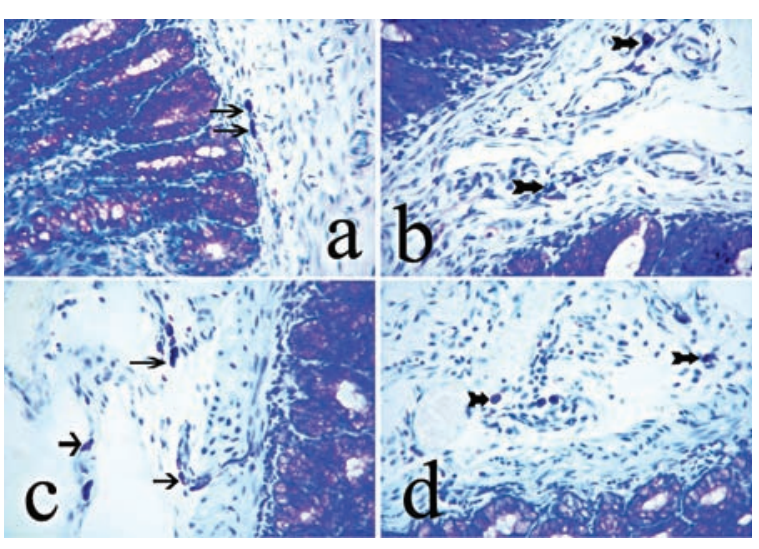

Figure 2. Appearance of mast cells of the colon sections. (A) Control group, (B) Royal Jelly group, (C) Colitis group, (D) Colitis + Royal Jelly group, Arrows: mast cells. Magnification $=180 \mathrm{X}$. Toluidine blue.

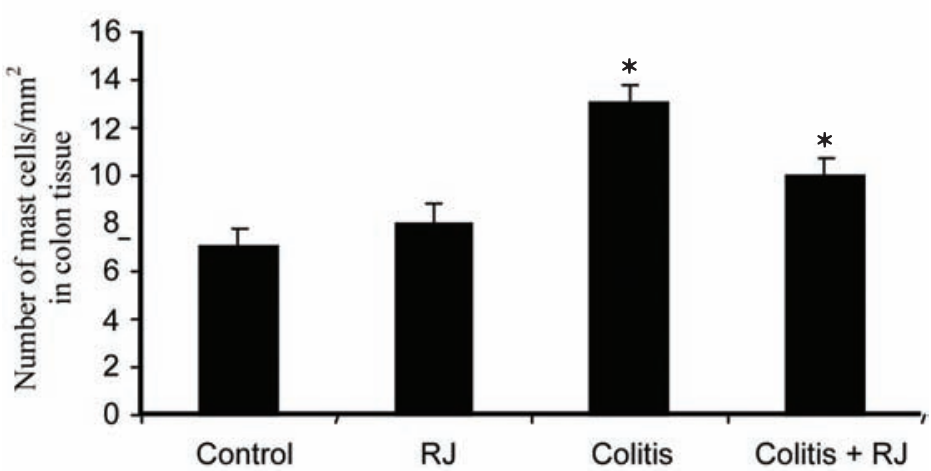

Figure 3. Number of colonic mast cells in control rats, RJ-treated rats and rats with acetic acid-induced colitis, without and with royal jelly treatment $(*$ significant at $\mathrm{P}<0.05)$.

\section{Discussion}

This study demonstrates for the first time that RJ has beneficial effects on the colon of rats with acetic acid-induced colitis. Introduction of acetic acid into the colon lumen induced gross lesions in the mucosal part of the intestine and caused typical colitis damage, which was confirmed histomorphometrically by significant increases in diarrhoea, congestion and swelling. ${ }^{18}$ Pronounced destructive changes associated with ulcerative colitis and haemorrhages were also observed in the colon of rats with acetic acid-induced colitis.

Treatment of colitic rats with an oral dose of RJ gave a degree of recovery from acute colitis. The anti-colitogenic effects of RJ could be attributed to improvement of the antioxidant status of the animals due to an increase in mucin content of the colon mucosa. ${ }^{21}$ Polyphenolic compounds in their many forms are the main components responsible for the functional properties associated with many foods, such as antioxidant capacity ${ }^{22,23}$ and antiinflammatory capacity. ${ }^{24} \mathrm{RJ}$ contains polyphenolic compounds collected by bees from the plants where they gather nectar. ${ }^{25}$

Previous studies ${ }^{25,26}$ suggested that Nigella sativa oil could protect the gastric mucosa against ethanol-induced ulcer. Kanbur et al. $^{4}$ reported that RJ protects against liver damage induced by paracetamol.

RJ has been shown to exhibit anti-inflammatory, DNA-protective, ${ }^{27}$ and anti-tumour, ${ }^{28,29}$ effects in experimental animals. Hamerlinck ${ }^{30}$ reported that $\mathrm{RJ}$ exhibited immunomodulatory properties by stimulating antibody production and immunocompetent cell proliferation in mice or by depressing humoral immune func- tions in rats. Another report indicated that the protection imparted by RJ ingestion could be partly attributed to the presence of neopterin in RJ. ${ }^{30}$ The protection afforded by RJ against the immunosuppression produced by increased PGE2 levels has been demonstrated in studies in vivo ${ }^{31}$ and in vitro. ${ }^{27}$

El-Nekeety et al. ${ }^{9}$ found a potential protective effect of RJ against the toxic hazards of fumonisins. Kamakura et al. ${ }^{32}$ reported that RJ in the diet decreased the gene expression of cytochrome P450 4A14 (CYP4A14) enzymes and detoxifying enzymes, which catalyse peroxidation of endogenous lipids, and increased the gene expression of glutathione S-transferase and glutathione peroxidase.

Ethanol has been proven to cause gastric damage, an effect confirmed histomorphometrically by significant increases in the number of MC and gastric erosions. ${ }^{33}$ In the present study, acetic acid-induced colitis caused pronounced destructive changes associated with haemorrhage in the colon of affected rats, as well as increasing number of MC (Figure $2 \mathrm{C}$ ). The ulcerative erosions in colon tissues of rats with acetic acid-induced colitis decreased when the animals were treated with RJ (Figure $2 \mathrm{D})$. In addition, RJ prevented any increase in the number of MCs. Oral treatment with an aqueous solution of RJ (150 mL kg-1) demonstrated a good level of colitis protection.

These findings are in good agreement with recent results presented by El-Dakhakhny et al. ${ }^{26}$ and Kanter et al. ${ }^{34}$ who found that Nigella sativa had a gastroprotective action in an ethanol-induced ulceration model.

Gebbers et al..$^{35}$ observed an increase in the number of IgE positive plasma cells and the appearance of intraepithelial MCs in patients with rectal spirochaetosis. Morris et al..$^{36}$ suggested that MCs numbers increased in inflamed tissues 3-4 weeks after colitis induction. In other studies, an increased MC count in the 5-20 day period ${ }^{37}$ and an elevated MC protease-2 (RMPC-2) level at 3 weeks were reported in colonic tissue taken from TNBS rats. ${ }^{38} \mathrm{Xu}$ et al. ${ }^{37}$ reported that MC numbers in the colon of Sabra rats with TNBS-induced colitis were lower during the first five days after induction.

As a result, while acetic acid application caused damage to the colon mucosa of rats, treatment with RJ was found to diminish the harmful effects of acetic acid. Although it has been considered that it might exert the benefits through its antioxidant features, the exact mechanism of effect is yet unknown. In conclusion, it could be suggested that the efforts to focus on the effect mechanism/s of RJ and other traditional medicinal supplements may provide new opportunities for the development of useful drugs.

\section{References}

1. Porath D, Riegger C, Drewe J, Schwager J. Epigallocatechin-3-gallate impairs chemokine production in human colon epithelial cell lines. J Pharmacol Exp Ther 2005; 315:1172-80.

2. Chen C, Shen G, Hebbar V, Hu R, Owuor ED, Kong AN. Epigallocatechin-3-gallate-induced stress signals in HT-29 human colon adenocarcinoma cells. Carcinogenesis 2003; 24:1369-78.

3. Katiyar SK, Mukhtar H. Tea antioxidants in cancer chemoprevention. J Cell Biochem Suppl 1997;27:59-67.

4. Kanbur M, Eraslan G, Beyaz L, Silici S, Liman BC, Altınordulu et al. The effects of 
royal jelly on liver damage induced by paracetamol in mice. Exp Toxicol Pathol 2009;61:123-32.

5. Karaali A, Meydanoglu F, Eke D. Studies on composition, freeze-drying and storage of Turkish royal jelly. J Apic Res 1998;27:182-5.

6. Bloodworth BC, Harn CS, Hock CT, Boon YO. Liquid chromatographic determination of trans-10-hydroxy-2-decenoic acid content of commercial products containing royal jelly. J AOAC Int 1995;78:1019-23.

7. Taniguchi Y, Kohno K, Inoue S, Koya-Miyata $\mathrm{S}$, Okamoto I, Arai N et al. Oral administration of royal jelly inhibits the development of atopic dermatitis-like skin lesions in NC/Nga mice. Int Immunopharmacol 2003; 3:1313-24.

8. Okamoto I, Taniguchi Y, Kunikata T, Kohno K, Iwaki K, Ikeda M et al. Major royal jelly protein 3 modulates immune responses in vitro and in vivo. Life Sci 2003;73:2029-45.

9. El-Nekeety AA, El-Kholy W, Abbas NF, Ebaid A, Amra HA, Abdel-Wahhab MA. Efficacy of royal jelly against the oxidative stress of fumonisin in rats. Toxicon 2007;50:256-69.

10. Bischoff SC, Wedemeyer J, Herrmann A, Meier PN, Trautwein C, Cetin Y et al. Quantitative assessment of intestinal eosinophils and mast cells in inflammatory bowel disease. Histopathology 1996; 28:1-13.

11. Lorentz A, Schwengberg S, Mierke C, Manns MP, Bischoff SC. Human intestinal mast cells produce IL-5 in vitro upon IgE receptor cross-linking and in vivo in the course of intestinal inflammatory disease. Eur J Immunol 1999;29:1496-503.

12. Gelbmann CM, Mestermann S, Gross V, Kollinger M, Scholmerich J, Falk W. Strictures in Crohn's disease are characterised by an accumulation of mast cells colocalised with laminin but not with fibronectin or vitronectin. Gut 1999;45: 210-7.

13. Bischoff SC, Lorentz A, Schwengberg S, Weier G, Raab R, Manns MP. Mast cells are an important cellular source of tumour necrosis factor alpha in human intestinal tissue. Gut 1999;44:643-52.

14. Inamura $\mathrm{H}$, Kashiwase $\mathrm{Y}$, Morioka $\mathrm{J}$, Suzuki K, Igarashi Y, Kurosawa M. Accumulation of mast cells in the interstitium of eosinophilic colitis. Allergol Immunopathol (Madr) 2006;34:228-30.

15. Kashiwase PY, Inamura $\mathrm{H}$, Morioka J, Igarashi Y, Kawai-Kowase K, Kurosawa M. Quantitative analysis of mast cells in benign and malignant colonic lesions: Immunohistochemical study on formalin- fixed, paraffin-embedded tissues. Allergol Immunopathol (Madr) 2008;36:271-6.

16. Bischoff SC, Schwengberg S, Wordelmann K, Weimann A, Raab R, Manns MP. Effect of c-kit ligand, stem cell factor, on mediator release by human intestinal mast cells isolated from patients with inflammatory bowel disease and controls. Gut 1996;38: 104-14.

17. Sellge G, Bischoff SC. Isolation, culture, and characterization of intestinal mast cells. Methods Mol Biol 2006;315:123-38.

18. Kang JW, Kim TW, La JH, Sung TS, Kim HJ, Kwon YB et al. Electroacupuncture ameliorates experimental colitis induced by acetic acid in rat. J Vet Sci 2004;5:189-95.

19. Fakhfouri G, Rahimian R, Daneshmand A, Bahremand A, Rasouli MR, Dehpour AR et al. Granisetron ameliorates acetic acidinduced colitis in rats. Hum Exp Toxicol 2010;29:321-8.

20. Enerback L. Mast cell heterogeneity: the evolution of the concept of a specific mucosal mast cell. In mast cell differentiation and heterogeneity, edited by Befus AD, Bienenstock J, Denburg JA, New York, Raven Press, USA, 1986.

21. Nieto N, Torres MI, Rios A, Gil A. Dietary polyunsaturated fatty acids improve histological and biochemical alterations in rats with experimental ulcerative colitis. J Nutr 2002;132:11-9.

22. Kerem Z, Chetrit D, Shoseyov 0, RegevShoshani G. Protection of lipids from oxidation by epicatechin, trans-resveratrol, and gallic and caffeic acids in intestinal model systems. J Agric Food Chem 2006; 54:10288-93.

23. Almaraz-Abarca N, da Graça Campos M, Avila-Reyes JA, Naranjo-Jiménez N, Herrera Corral J, Gonzalez-Valdez LS. Antioxidant activity of polyphenolic extract of monofloral honeybee collected pollen from mesquite (Prosopis juliflora, Leguminosae). J Food Compost Anal 2007; 20:119-124.

24. Wu Y, Zhou C, Li X, Song L, Wu X, Lin W et al. Evaluation of antiinflammatory activity of the total flavonoids of Laggera pterodonta on acute and chronic inflammation models. Phytother Res 2006;20:585-90.

25. Fiorani M, Accorsi A, Blasa M, Diamantini G, Piatti E. Flavonoids from italian multifloral honeys reduce the extracellular ferricyanide in human red blood cells. J Agric Food Chem 2006;54:8328-34.

26. El-Dakhakhny M, Barakat M, Abd El-Halim M, Aly SM. Effects of Nigella sativa oil on gastric secretion and ethanol induced ulcer in rats. J Ethnopharmacol 2000;72:
299-304.

27. Kohno K, Okamoto I, Sano 0, Arai N, Iwaki $\mathrm{K}$, Ikeda M et al. Royal jelly inhibits the production of proinflammatory cytokines by activated macrophages. Biosci Biotechnol Biochem 2004;68:138-45.

28. Nakaya M, Onda H, Sasaki K, Yukiyoshi A, Tachibana H, Yamada K. Effect of royal jelly on bisphenol A-induced proliferation of human breast cancer cells. Biosci Biotechnol Biochem 2007;71:253-5.

29. Fujii A. Pharmacological effect of royal jelly. Honeybee Sci 1995;16:97-104.

30. Hamerlinck FF. Neopterin: a review. Exp Dermatol 1999;8:167-76.

31. Oka H, Emori Y, Kobayashi N, Hayashi Y, Nomoto K. Suppression of allergic reactions by royal jelly in association with the restoration of macrophage function and the improvement of Th1/Th2 cell responses. Int Immunopharmacol 2001;1:521-32.

32. Kamakura M, Maebuchi M, Ozasa S, Komori M, Ogawa T, Sakaki T et al. Influence of royal jelly on mouse hepatic gene expression and safety assessment with a DNA microarray. J Nutr Sci Vitaminol (Tokyo) 2005;51:148-55.

33. Kahraman A, Erkasap N, Köken T, Serteser M, Aktepe F, Erkasap S. The antioxidative and antihistaminic properties of quercetin in ethanol-induced gastric lesions. Toxicology 2003;183:133-42.

34. Kanter M, Coskun 0, Uysal H. The antioxidative and antihistaminic effect of Nigella sativa and its major constituent, thymoquinone on ethanol-induced gastric mucosal damage. Arch Toxicol 2006;80: 217-24.

35. Gebbers J0, Ferguson DJ, Mason C, Kelly P, Jewell DP. Spirochaetosis of the human rectum associated with an intraepithelial mast cell and IgE plasma cell response. Gut 1987;28:588-93.

36. Morris GP, Beck PL, Herridge MS, Depew WT, Szewczuk MR, Wallace JL. Hapteninduced model of chronic inflammation and ulceration in the rat colon. Gastroenterology 1989;96:795-803.

37. Xu X, Weksler-Zangen S, Pikarsky A, Pappo 0, Wengrower D, Bischoff SC et al. Mast cells involvement in the inflammation and fibrosis development of the TNBS-induced rat model of colitis. Scand J Gastroenterol 2002;37:330-7.

38. Fukumoto Y, Kasai H, Takahashi H, Sugiyama H, Hase N, Kaneko $\mathrm{H}$ et al. The role of mast cells in the development of 2 , 4, 6-trinitrobenzene sulfonic acid-induced colitis in rats. Scand $\mathrm{J}$ Gastroenterol 2002;37:555-60. 